For personal use only. Not to be reproduced without permission of the publisher (editorial@gabi-journal.net).

\section{Effect of naming on pharmacists' perceptions and dispensing of biosimilars}

A study of pharmacists investigated their perceptions of biosimilar naming conventions and the impact it might have on their dispensing habits [1]. The study found that pharmacists had a preference for distinguishable names. However, using the same names for interchangeable biologicals would make pharmacists more likely to dispense biosimilars.

A growing number of biosimilars are set to hit the US market in the coming years. The increase in availability of such agents is being met with a number of questions regarding the regulations that will govern them. The US Food and Drug Administration (FDA) has attempted to answer some of these questions, including those related to biosimilar naming. The agency issued draft guidance on the non-proprietary naming of biological products in August 2015 [2]. However, the guidance continues to be in flux and does not address naming for products given an interchangeable designation.

This study was carried out jointly by the Academy of Managed Care Pharmacy (AMCP) and the Hematology/Oncology Pharmacy Association (HOPA). It aimed to determine pharmacists' perceptions of biosimilar naming conventions and the impact it might have on pharmacists' confidence to dispense biosimilars. In addition, the study aimed to measure the burden that is created by laws and regulations requiring pharmacists to complete post-dispense notifications.

The cross-sectional survey of 781 pharmacists was conducted using an online survey software program. Participants reported preference for the use of a non-proprietary base with a designated suffix (48.1\%) compared to the use of a non-proprietary base alone (26.3\%), non-proprietary base plus a prefix (14.2\%), or a unique brand name (11.4\%). This preference, however, did not correlate with confidence levels reported when dispensing a biosimilar in place of the reference biological, with the largest percentage of participants reporting high levels of confidence when the products shared the same non-proprietary name (62.9\%). This suggests that sharing the same non-proprietary name may improve pharmacist confidence in biosimilars at the point of dispensing. The majority of participants (64.9\%) also expected an increased burden when required to provide a post-dispense notification to prescribers when dispensing biosimilars.

The preference for unique names for biologicals correlates with a survey carried out on pharmacists in the US by the Alliance for Safe Biologic Medicines (ASBM) [3]. That survey found that the majority of responders (68\%) thought that FDA should require a distinct non-proprietary scientific name for every biological product - originator or biosimilar. While a total of $77 \%$ of respondents thought that a manufacturer-specific suffix should be included in the name of each biological product [3].

The issue of naming for biologicals is a contentious one. Advocates for distinct names include the Biologics Prescribers Collaborative (BPC) and the ASBM. The Generic Pharmaceutical Association (GPhA), on the other hand, believes that different names could 'erect barriers to patient access to new, more affordable medicines, and jeopardize their safety'; whilst the
AMCP has said that distinct names could result in 'lower market adoption and cost-savings' from biosimilars [4].

The GPhA has also pointed out that Europe has approved biosimilars with the same non-proprietary names as their reference biologicals for more than six years in a system that has proven effective. Biosimilars have also been successfully tracked in the marketplace using their brand name and other identifiers currently in place for product recognition, meaning a separate non-proprietary name is not necessary for keeping track of biosimilars once they are on the market [5].

The World Health Organization (WHO) has proposed a Biological Qualifier (BQ) that would be used in conjunction with the international non-proprietary name (INN) and would consist of a random alphabetic code, made up of four random consonants [5]. The International Generic and Biosimilar medicines Association (IGBA) has expressed concerns, however, that the WHO proposal is 'meaningless, unmemorable, confusing [and] unnecessarily complicated'. It also believes that retrospective application of BQs to already authorized products may lead to discrimination and be anticompetitive [6].

The ASBM also believes that the use of four-digit codes that are memorable and logical would better promote manufacturer accountability, giving Zarxio (filgrastim-sndz) as an example. The FDA draft guidance proposes a meaningless four-letter suffix. This, says the ASBM, 'creates an unnecessary barrier to the use of distinguishable suffixes' [4].

In the survey carried out by the AMCP and HOPA, when asked directly, pharmacists reported preference for a non-proprietary proper name with a designated suffix for biosimilars. However, use of such a naming strategy was associated with a decrease in confidence of substituting a biosimilar for the originator biological. The author therefore concluded that this may impact the 'willingness of some pharmacists to dispense biosimilars' or may result in pharmacists transferring this lower level of confidence in the product to the patient. 'This effect will be minimized if interchangeable biologics share the same nonproprietary name as the reference biologics'. Additional research is needed to determine the overall impact this may have on the actual use of biosimilars.

\section{Competing interests: None.}

Provenance and peer review: Article abstracted based on published research paper [1] by Dr D Tomaszewski, edited by Michelle Derbyshire, PhD, GaBI Online Editor; internally peer reviewed.

\section{References}

1. Tomaszewski D. Biosimilar naming conventions: pharmacist perceptions and impact on confidence in dispensing biologics. J Manag Care Spec Pharm. 2016;22(8):919-26.

2. GaBI Online - Generics and Biosimilars Initiative. FDA issues draft guidance on naming biosimilars [www.gabionline.net]. Mol, Belgium: Pro Pharma Communications International; [cited 2016 Nov 22]. Available from: www.gabionline. net/Guidelines/FDA-issues-draft-guidance-on-naming-biosimilars

3. Schneider P, Reilly MS. Naming and labelling of biologicals - the perspective of hospital and retail pharmacists. Generics and Biosimilars Initiative Journal (GaBI Journal). 2016;5(3):151-5. doi:10.5639/gabij.2016.0504.040

References 4 to 6 can be found on page 179

Submitted: 21 November 2016; Revised: 22 November 2016; Accepted: 24 November 2016; Published online first: 30 November 2016 
Effect of naming on pharmacists' perceptions and dispensing of biosimilars References (please see the full manuscript on page 185)

4. GaBI Online - Generics and Biosimilars Initiative. Comments on FDA's guidance on naming biologicals [www.gabionline.net]. Mol, Belgium: Pro Pharma Communications International; [cited 2016 Nov 22]. Available from: www. gabionline.net/Biosimilars/General/Commentson-FDA-s-guidance-on-naming-biologicals
5. GaBI Online-Generics and Biosimilars Initiative. WHO issues draft proposal for its biological qualifier [www.gabionline.net]. Mol, Belgium: Pro Pharma Communications International; [cited 2016 Nov 22]. Available from: www.gabionline. net/Policies-Legislation/WHO-issues-draftproposal-for-its-biological-qualifier
6. GaBI Online-Generics and Biosimilars Initiative. IGBA opposes WHO biological qualifier [www. gabionline.net]. Mol, Belgium: Pro Pharma Communications International; [cited 2016 Nov 22]. Available from: www.gabionline.net/Biosimilars/ General/IGBA-opposes-WHO-biological-qualifier DOI: 10.5639/gabij.2016.0504.048

Copyright @ 2016 Pro Pharma Communications International 